\title{
Research Progress on Causes and natural cut-off of distorted river bends
}

\author{
ZHAO Wanjie ${ }^{1,2}$, XU Linjuan ${ }^{1,3}$, LI Junhua ${ }^{1}$, WANG Yuanjian ${ }^{1}$, JIANG Enhui $^{1, *}$ \\ ${ }^{1}$ Yellow River Institute of Hydraulic Research, Yellow River Conservancy Commission, Zhengzhou 450003, China; ${ }^{2}$. North China \\ University of Water Resources and Electric Power, Zhengzhou 450045, China; ${ }^{3}$ State Key Laboratory of Hydro-Science and \\ Engineering, Department of Hydraulic Engineering, Tsinghua University, Beijing 100084, China
}

\begin{abstract}
In recent years, the distorted river bends occurs frequently in the lower reaches of the Yellow River, and the critical catastrophe occurs of natural cut-off under the action of flood scouring during flood season, which directly affects the plane shape of the river channel and the flood control safety of local reach. By collecting a large number of literature and combining existing research results, the causes of the deformed rivers and the natural cutting phenomenon are reviewed. The formation of the distorted river bends is mainly related to the incompatibility of the upstream water and sediment inflow conditions with the river boundary conditions, the formation of local anti-scour nodes (such as clay mouth) and the emergence or control engineering, and the different anti-scour properties of the riverbed leading to the main stream swing. In the development and evolution process of river bays, natural cutting curve occupies an important position, and there are three typical forms, such as erosion ditch type, bank collapsing type and die cutting type, and its cutting ratio is 1.6-6.9. In the future, we should study the composition of the river bed, study the causes and mechanism of the abnormal river regime in the lower Yellow River more deeply, predict the trend of the abnormal river regime scientifically, and evaluate the damage.
\end{abstract}

\section{Research background}

Generally speaking, the river flows downstream in the form of curves and straight lines in the longitudinal direction, and in the plane it is one or more strands. For multi-share situation, the water flow per share in the vertical is also mostly curved and straight, along the way there will be convergence, shareholding situation. The curved sections are mostly smooth, and the flow direction in the curved sections is consistent with the general flow direction of the river. During the evolution of the river regime, there will be some deformed river bays ${ }^{[1]}$.

The abnormal river regime is a special natural phenomenon of the river regime evolution in the lower Yellow River ${ }^{[2]}$. Because of the irregularity of the abnormal River Bay evolution, the distorted river bends mainly has the following hazards: (1) Threatening the safety of embankment: the distorted river bends is easy to cause the break of embankment. (2) Threatening the safety of river regulation project: The distorted river bends makes the existing water flow can not be carried out according to the engineering regulation line, causes the project to break off, causes the control and guidance project to lose the control of the main slide, stabilizes the river regime, and is also very prone to major engineering risks. (3) Threatening the safety of beach areas: after the occurrence of deformed bays, the water flows directly into the beach areas, resulting in the collapse of farmland and villages in the beach areas, which poses a great threat to the safety of people's lives and property in the beach areas. (4) Great changes have taken place in the river regime. Therefore, it attracts people's attention.

\section{Research progress of distorted river bends}

\subsection{Causes of distorted river bends}

Since the 1990s, many domestic scholars have studied the phenomenon of distorted river bends in the lower reaches of the Yellow River. Hu Yisan et al. ${ }^{[3]}$ studied the bending of the deformed bay before the regulation of the lower Yellow River in 1966, and believed that the distorted river bends was formed due to the existence of erosion-resistant clay layer (clay mouth) in the river course and the oneway development of the river crest during the change of river regime; $\mathrm{Xu}$ Jiongxin et al. ${ }^{[4]}$ believe that the formation mechanism of the wandering reach malformed Bay is the formation and outcropping of local anti-scour nodes (such as clay mouth), which makes the upstream and downstream curved roof develop unevenly and form a malformed bay, and the second is the formation of a malformed Bay in the process of self-adjustment caused by the flow reduction; Jiang Enhui et al. ${ }^{[5]}$ hold that the formation of the malformed Bay is due to the two reasons mentioned above, that is, the malformed river regime

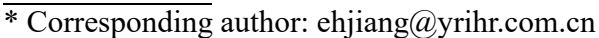


caused by the swing of the main stream due to the different Anti-Scourability of the riverbed. Three factors affecting the formation of the deformed Bay are analyzed: the influence of the process of water and sediment inflow, the influence of the form of the riverbed and the influence of the composition of the riverbed. From the point of view of soil mechanics, the impact resistance of clay layer is studied.

In recent years, the abnormal river regime occurs frequently in the lower reaches of the Yellow River ${ }^{[6]}$. Niu Yuguo et al. ${ }^{[7]}$ analyzed the causes of the abnormal river regime by using the observed data. In the upper reaches of the East Batou River of the Yellow River, the main causes of the abnormal river regime such as oblique River and transverse River are the wandering channel, shallow width and large transverse ratio drop. The transverse ratio drop in the lower reaches of the Yellow River is more than two times of the longitudinal ratio drop. The standard of traverse planning and engineering fortification for river course control and guidance works in the lower Yellow River is $5000 \mathrm{~m}^{3} / \mathrm{s}$ or $4000 \mathrm{~m}^{3} / \mathrm{s}$. In recent years, the discharge of the lower reaches of the Yellow River is mostly less than $1000 \mathrm{~m}^{3} / \mathrm{s}$, and the Xiaolangdi Reservoir has a small discharge, a long time and even discharge of clear water. It is difficult for the river regime to follow the direction of the river control and guidance engineering. The river diversion project partially lost control of the river regime. The beaches on both sides of the channel (mostly composed of coarse sand) have weak antiscouring capacity. Once the water flows along the river, it is easy to collapse. Under the action of bend circulation and water energy, most coarse sediments are deposited into bed sand, and some fine sediments are washed downstream. Repeatedly, the bank collapse intensifies, and the abnormal river regime will develop rapidly. Very few sections of the river also have silt layer (or clay layer), strong anti-scouring ability, will affect the development of normal River regime, but also easy to form abnormal river regime.

Zhang Linzhong et al. ${ }^{[8]}$ studied the morphology, cause and harm of the deformed bays in the lower Yellow River by using the measured data and model experiment results. It was pointed out that the deformed bays in the lower Yellow River mainly have the following forms: 1) Sshaped, 2) inverted S-shaped, 3) $\Omega$-shaped, 4) Z-shaped, 5) cross-river and 6) oblique river. The formation conditions, development process, duration and evolution law of abnormal river regime in the lower Yellow River are analyzed. It is considered that the formation conditions are affected by the mobility of the river bed, the composition of riverbed sediment and the water and sediment conditions $^{[9]}$.

The abnormal river regime in the lower reaches of the Yellow River has occurred frequently, which poses a serious threat to flood safety. Wu Tian et al. ${ }^{[10]}$ introduce the recent changes of river regime and the trend of river regime development in Jiubao $\sim$ Weitan reach of the lower Yellow River. The causes of the abnormal river regime are further analyzed: Firstly, the incoming water and sediment in the upper reaches are less than before. Since 1949, the amount of water and sediment entering the section of Huayuankou has decreased to varying degrees. Secondly,
After the Xiaolangdi Dam reservoir was used, the water was released all the year round and the riverbed in the lower reaches of the Yellow River was strongly eroding. After the riverbed is scoured and cut down, the main channel becomes narrower and deeper. Once the small water sits in the bay, it is difficult to change the abnormal river regime by its own ability.

To sum up, the causes of the abnormal river regime are: first, the incompatibility of the incoming water and sediment conditions with the river boundary conditions results in the occurrence of the abnormal River regime; second, the formation and outcropping of local anti-scour nodes (such as clay mouth) or the engineering of control and guidance, resulting in the uneven development of the upper and lower bends and the formation of abnormal bays; third, the river bed quality is different from the scour resistance, leading to the main swing and forming the abnormal river regime.

\subsection{Natural cut-off and development}

During the 10 years before the river regulation in 1966, the Gaocun to Taochengpu reach of the lower Yellow River had formed a distorted Bay many times, and there were 7 large natural bending phenomena ${ }^{[7]}$. The lower reaches of the Yellow River in Zhengzhou, below the Jingguang Railway Bridge and above the Dongbatou River are also the rivers with deformed rivers, such as the abnormal river regime of Liuyuankou from 1981 to 1984 , the abnormal river regime of Wang'an from 1999 to 2005, the abnormal river regime of Dagong from 2003 to 2005, the abnormal river regime of Heigangkou from 2008 to 2009 , and the abnormal river regime of Weitan in 2012. In recent years, there are many abnormal river regimes above the Jingguang Railway Bridge, such as Dayulan abnormal river regime in 2011, Zaoshugou abnormal river regime in 2012, Dongan abnormal river regime in 2012 and Zhaogou abnormal river regime in 2013. Through analysis, it is found that the abnormal river regime is prone to occur in the uncontrolled reach and the engineering control reach with large longitudinal gradient. The occurrence time is mainly before flood season or after flood season.

The development of the abnormal river regime can be roughly divided into three stages, namely, the initial formation stage, the slowly changing stage and the cutting straight stage. When the existing river regime and the planned trend of the river regime are quite different, that is, the rising and falling of the river regime is obvious and the bend roof is moved out of the project, the abnormal river regime can be judged as the initial formation. When the bend roof which is not controlled by the project moves slowly upstream or downstream, the angle between the flow axis and the planned flow path axis increases gradually until it is greater than 65 degrees $^{[7]}$, the process belongs to the abnormal river regime slowly changing stage. At the later stage of the abnormal river regime slowly changing stage, S-shaped, Z-shaped, “几”-shaped or $\Omega$-shaped river regimes are often formed.

In the course of natural evolution of abnormal river regime, because of the concave bank scours and the convex bank deposits unceasingly, the distance between 
two adjacent bends on the same bank is gradually shortened, the bending amplitude is increased, and the water level difference is also significantly increased. When flooding occurs, floodplain flow occurs strong scouring at the bend neck, so it gradually develops into a new river, which is the cutting straight stage.

\subsection{Natural cut-off form and cutting parameters}

Natural bending is a catastrophic event in the evolution of meandering rivers. It is not only the end of the evolution of old bends, but also the starting point of the formation of new channels, and plays a key role in the dynamic process of the evolution of bays ${ }^{[11 \sim 13]}$. Li zhiwei and wang zhaoyan et al. ${ }^{[14]}$, through the interpretation of Google Earth satellite images, summarized three typical forms of natural cut-off curves (see figure 1) without considering the skim-beach cut-off curves of river bend top: erosion ditch type, bank collapsing type and die cutting type. Morphological statistics show that the ratio of neck width to average width of the bay is the erosion ditch type, the die cutting bank collapsing type and the bank collapsing type from large to small. The bend rate of the bend from high to low is the bank collapsing type, the die cutting bank collapsing type and the erosion ditch type. Different bending styles correspond to different bending rates. The dynamic condition of erosion ditch type is that many floods scour and cut the neck; the dynamic condition of bank collapsing type is that both sides of the neck of meandering flow collapse lead to the direct connection of upstream and downstream; the dynamic condition of die cutting type is that a high water level flood cut the neck directly.

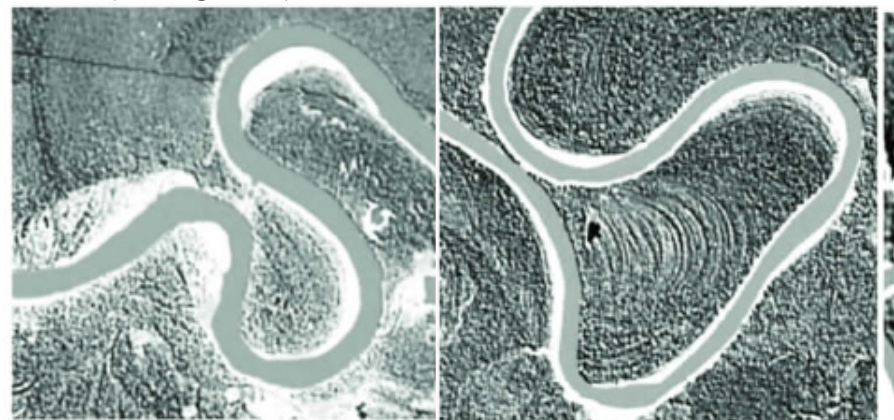

erosion ditch type(a) bank collapsing type(b)

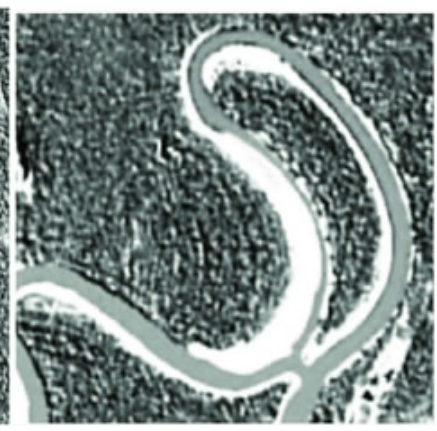

die cutting type(c)

Figure 1. Typical forms of natural cutoff

Zhang Linzhong ${ }^{[8]}$ et al. with the help of the measured data of natural bending ratio in the lower Yellow River, the ratio of natural bending in the lower Yellow River is 1.66.9, and the model test results of the Yellow River Institute of Water Conservancy in 2005 on the mechanism and scheme of river excavation in the wide channel of the lower Yellow River are studied. At the time of the model test research results, the generalized model was used to carry out the bending engineering test with a bending ratio of 3 to 7 , a section ratio of $1 / 10$ to $1 / 30$, and an inflow angle of $25^{\circ}$ or less. In the case of more than $90 \%$, success has been achieved. If the bending ratio is controlled by $3-$ 7 at the narrowest part of the abnormal bay, the probability of successful bending and the engineering benefit will be higher ${ }^{[15]}$.

The Yellow River Research Institute of Water
Conservancy and Hydropower has carried out a model test of river bending in the lower reaches of the Yellow River (see Table 1). The test shows that when the bending ratio is less than 3, $80 \%$ of the river diversion can not be developed; when the bending ratio is between 3.0 and 7.0, more than $90 \%$ of the river diversion can be developed and eventually passed through all large rivers. In the test group of successful river diversion, the diversion ratio increases as a whole after the river diversion, and reaches a maximum value at peak discharge, then decreases with the decrease of flood discharge, the diversion ratio also decreases. Finally, with the flood subsidence, the inlet of the old channel is silted high, but the diversion ratio reaches 1.0 (see Figure 2). The larger the cut-off ratio is, the larger the river diversion is, the faster the development will be, and the better the final diversion effect will be ${ }^{[16]}$.

Table 1. Test scheme of cut-off model

\begin{tabular}{ccc}
\hline Cutting ratio & Ratio of excavation area to final channel area & $\theta /\left(^{\circ}\right)$ \\
\hline 1.1 & $1 / 4$ & 5 \\
& $1 / 4$ & 25 \\
$1 / 4$ & 40 \\
1.4 & $1 / 7$ & 5 \\
3.0 & $1 / 10$ & 15 \\
& $1 / 30$ & 15 \\
& $1 / 4$ & 15 \\
7.0 & $1 / 4$ & 25 \\
& $1 / 10$ & 25 \\
& $1 / 30$ & 15 \\
\hline
\end{tabular}




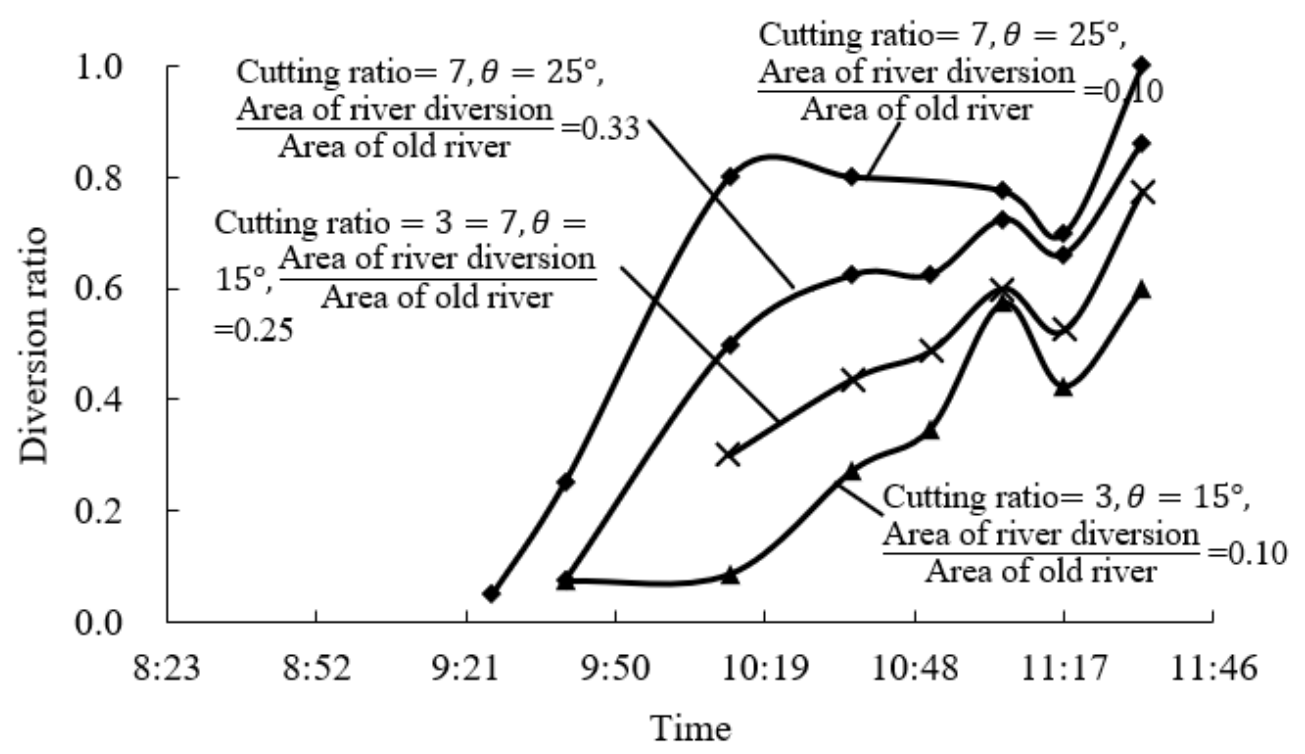

Figure 2. Variation of diversion ratio in different experimental groups

\section{Expectation}

According to the measured data and model test of natural bending in the lower reaches of the Yellow River, the bending can be successfully cut when the cutting ratio is controlled between 3.0 and 7.0, which provides a reference for manual bending in the future. At present, a great deal of research has been done on the changes of water and sediment inflow conditions, river morphology and so on, while few studies have been carried out on the river bed composition. More in-depth studies should be made on the trigger cause, formation process and evolution law of the river.

In the lower reaches of the Yellow River, the longitudinal gradient and the sediment composition of the river bed are relatively stable, while the discharge, velocity, transverse gradient of the river channel and the outlet height of the beach are variable. Therefore, to study the formation mechanism and causes of abnormal river regime in the lower Yellow River, it is necessary not only to study and analyze the variable factors such as discharge, transverse gradient and artificial boundary conditions, but also to predict the trend of abnormal river regime scientifically and evaluate the possible harm of abnormal River regime.

\section{Acknowledgments}

This research was supported by National Key R\&D Program of China (2018YFC0407400), and Supported by National Natural Science Foundation of China (51709123, 51479080, 51539004), and Supported by Special Basic Research Fund for Central Public Research Institutes (HKY-JBYW-2018-03), and Supported by Scientific and Technological Development Fund of Yellow River Institute of Hydraulic Research (HKF201706).

\section{Reference}

1. $\mathrm{Hu}$ Yisan. Deformed River Bend of Regime Evolution in the Lower Yellow River[J]. Yellow River, 2016, 38(10): 43-48.

2. Hu Chunhong, Chen Xunjian, Chen Jianguo,et al. Spatial distribution and its variation process of sedimentation in Yellow River[J]. Journal of Hydraulic Engineering, 2008, 39(5): 518-527.

3. Hu Yisan, Xiao Wenchang. The cutting bend before the regulation of the transitional reach in the lower Yellow River[J]. Yellow River, 1991, 13(10): 3032.

4. $\mathrm{Xu}$ Jiongxin, Lu Zhongchen, Liu Jixiang. Formative Cause of Distorted Bends in the Braided Lower Yellow River in the Process of Channel Shrinkage[J]. Journal of Sediment Research, 2000, (3): 36-41.

5. Jiang Enhui, Cao Yongtao, Zhang Linzhong, et al. Study on the evolution regularity and mechanism of the wandering reach of the lower Yellow River[M]. Beijing: China Water Conservancy and hydropower Press, 2006.

6. Sun Zanying, Ye Chunsheng, Qu Shaojun,et al. Mechanism and countermeasures of the influence of deformed river potential on river discharge capacity[J]. Yellow River, 2009, 31(8): 13-14.

7. Niu Yuguo, Duanmu Liming, Zhou Nianbin, et al. Causes of abnormal river in lower Yellow River and its control measures[J]. Yellow River, 2013, 35(8): 1-3, 9 .

8. Zhang Linzhong. Analysis on the Shape of Irregular River Bend and the Feasibility of Bend Cut-Off in the Lower Yellow River[J]. Yellow River, 2013, 35(9): 41-42, 45.

9. Zhang Linzhong, Dong Qinghua, Wan Qiang. Study on the Evolutional Law and the River 
Training Measures of the Freakish River Regime in the Lower Yellow River[J]. Yellow River, 2015, 37(11): 32-35.

10. Wu Tian, Meng Yao, Li Songping, et al. Genesis and regulation scheme of deformed river in JiubaoYiu-Wei beach in lower Yellow River[J]. Water Resources \& South-North Water diversion, 2015, (6): 34-35.

11. Stolum H H. River meandering as a selforganization process[J]. Science, 1996, 271( 5256) : 1710-1713.

12. Camporeale C, Perucca E, R idolfi L. Significance of cutoff in meandering river dynamics[J]. Journal of Geophysical Re-search- Atmospheres, 2008, 113( F1) : 548-562.

13. Frascati A, Lanzoni S. Long-term river meandering as a part of chaotic dynamics? A contribution from mathematical mod-eling $[\mathrm{J}]$. Earth Surface Processes and Landforms, 2010, 35(7) : 791-802.

14. Li Zhiwei Wang Zhaoyin Li Wenzhe .The form of cutting bend and geometrical critical shape of alluvial river bend[J]. Journal of Sichuan University (Engineering Science Edition), 2012, 44(01): 82-87.

15. Zhang Yuanlong, Zhang Linzhong, Huang Honghai, et al. Study on key technology of wide channel cutting in lower Yellow River[C]. // Proceedings of the Eleventh National Maritime Science and Technology Symposium. Shanghai: $<<$ Shipbuilding of China $>>$ Edition, 2006: 232237.

16. Zhang Linzhong, Qiao Jingshun, Zhao Xinjian et al. Study on the Effect of Bend Cut-off Ratio on the Development of the Distributary Channel in the Lower Yellow River[J]. Yellow River, 2013, 35(4) : $1-2$. 